\title{
Characterisation and Mutagenesis Study of An Alternative Sigma Factor Gene ( $h r p L$ ) from Erwinia mallotivora Reveal Its Central Role in Papaya Dieback Disease
}

\author{
Amin-Asyraf Tamizi ${ }^{1}$, Norliza Abu-Bakar ${ }^{1, *}$, Aimera-Farhana Samsuddin ${ }^{2}$, Lina Rozano ${ }^{1}$, \\ Rohaiza Ahmad-Redzuan ${ }^{1}$ and Abdul-Munir Abdul-Murad ${ }^{2}$ \\ 1 Agri-Omics and Bioinformatics Programme, Biotechnology and Nanotechnology Research Centre, \\ Malaysian Agricultural Research and Development Institute Headquarters, \\ Serdang 43400, Selangor, Malaysia; aminasyraf@mardi.gov.my (A.-A.T.); \\ rozalina@mardi.gov.my (L.R.); rohaiza@mardi.gov.my (R.A.-R.) \\ 2 School of Biosciences and Biotechnology, Faculty of Science and Technology, Universiti Kebangsaan Malaysia, \\ Bangi 43600, Selangor, Malaysia; aimera.farhana@gmail.com (A.-F.S.); munir@ukm.edu.my (A.-M.A.-M.) \\ * Correspondence: lizaab@mardi.gov.my; Tel.: +60-3-8953-6102
}

Received: 12 August 2020; Accepted: 22 September 2020; Published: 3 October 2020

check for updates

Simple Summary: Erwinia mallotivora is the causal agent of papaya dieback disease in Malaysia, and its pathogenicity is less appreciated, especially from the molecular perspective. Our previous investigations proved that the $h r p L / r p o E$ gene was one of the significant differentially expressed genes (DEGs) during early infection of E. mallotivora in papaya, suggesting this particular gene is important for infection. In this study, an in-depth analysis was performed using bioinformatics software on hrpL from E. mallotivora (EmhrpL) and its encoded protein (EmHrpL) obtaining crucial information including the conserved function and sequence motif, protein structural similarity with related homologs, and the possibility of being inhibited by a cognate inhibitor. Moreover, knockout (insertional mutational on DNA sequence) of the $h r p L$ gene had caused mutant E. mallotivora $(\Delta E m h r p L)$ to be avirulent in four-month-old papaya plants. Here, the conclusion was that EmHrpL is indeed a necessary factor in E. mallotivora pathogenicity, and the findings on the potential inhibitor of this protein are useful for future studies to formulate a papaya dieback disease management programme.

\begin{abstract}
The alternative sigma $(\sigma)$ factor E, RpoE or HrpL, has been reported to be involved in stressand pathogenicity-related transcription initiation in Escherichia coli and many other Gram-negative bacteria, including Erwinia spp. and Pseudomonas spp. A previous study identified the hrpL/rpoE transcript as one of the significant differentially expressed genes (DEGs) during early E. mallotivora infection in papaya and those data serve as the basis of the current project. Here, the full coding DNA sequence (CDS) of hrpL from E. mallotivora (EmhrpL) was determined to be $549 \mathrm{bp}$ long, and it encoded a $21.3 \mathrm{kDa}$ HrpL protein that possessed two highly conserved sigma-70 $\left(\sigma^{70}\right)$ motifs- $\sigma \mathrm{R} 2$ and $\sigma \mathrm{R} 4$. Nucleotide sequence alignment revealed the $h r p L$ from E. mallotivora shared high sequence similarity to $r p o E / h r p L$ from E. tracheiphila (83\%), E. pyrifoliae (81\%), and E. tasmaniensis (80\%). Phylogenetics analysis indicated $h r p L$ from E. mallotivora to be monophyletic with rpoEs/hrpLs from Pantoea vagans, E. herbicola, and E. tracheiphila. Structural analysis postulated that the E. mallotivora's alternative $\sigma$ factor was non-transmembranic and was an extracytoplasmic function (ECF) protein-characteristics shared by other $\sigma$ factors in different bacterial species. Notably, the protein-protein interaction (PPI) study through molecular docking suggested the $\sigma$ factor could be possibly inhibited by an anti- $\sigma$. Finally, a knockout of $h r p L$ in E. mallotivora $(\triangle E m h r p L)$ resulted in avirulence in four-month-old papaya plants. These findings have revealed that the $h r p L$ is a necessary element in E. mallotivora pathogenicity and also predicted that the gene can be inhibited by an anti- $\sigma$.
\end{abstract}


Keywords: bacterial disease; Malaysia; papaya; transcriptome sequencing

\section{Introduction}

Alternative RNA polymerase sigma $(\sigma)$ factors (Rpo) are essential small proteins required for translational initiation of other genes in certain pathways specifically related to stress tolerance, bacterial-host interaction, and pathogenicity [1-4]. Lambert et al. [5] proved that Rpo is important for specific binding of RNA polymerase to specific gene promoters and its crucial role in disease incidence has been discussed by Helmann [6]. Prior to the initiation of gene expression of a certain pathway, RNA polymerase recruits a sigma factor (along with a few other factors) and forms a holoenzyme before it can bind to the gene promoter region [6].

In several Gram-negative pathogens-as reported in the Shigella, Salmonella, Erwinia, and Pseudomonas genera-the type III secretion system (T3SS) is the major conserved infection mechanism employed during pathogenicity $[7,8]$. The T3SS is a complex system where a group of hypersensitive response and pathogenicity $(h r p)$ genes work synchronously during a disease event. Naturally, this system is bound to RNA polymerase transcription initiation which involves the Rpo $[6,7,9]$. Once initiated, the T3SS transcribes various protein elements in the hrp family complex to assemble tiny needles known as harpins, which are used to contact host cells [10]. The secretion of effectors through T3SS is said to occur when various proteins, lytic enzymes, and ions are transferred across the cell membranes from the pathogen into the host cells, marking the start of an invasion [10-12].

The gene encoding an Rpo is also referred to as $h r p L$ depending on the bacterial species $[6,13]$. The alternative $\sigma$ factor plays a major role in regulating the T3SS gene by interacting with -10 and -35 motifs on the promoter region of the regulated genes [14]. It was demonstrated that the HrpL alternative $\sigma$ factor activates HrpA, HrpN, and DspE effector genes in D. dadantii (formerly known as Erwinia chrysanthemi), which is a pathogen responsible for soft rot disease in several important crops $[15,16]$.

Erwinia mallotivora has been identified as the pathogen that causes papaya dieback disease in Malaysia, responsible for the decline in national papaya export for almost two decades [17]. Nevertheless, knowledge of the virulence mechanism of E. mallotivora at the molecular level is relatively limited. In E. mallotivora, T3SS was first found from its draft genome sequence [18] and later reported in proteomics and transcriptomics studies $[19,20]$. Based on these, herein is a detailed description of a single gene associated with pathogenicity, $h r p L$, from E. mallotivora, which is thought to be the 'master control' of the T3SS. In this article, the gene $h r p L$ from E. mallotivora is referred to as EmhrpL and its protein is referred to as EmHrpL.

\section{Materials and Methods}

\subsection{Retrieval of EmhrpL Gene Sequence}

The nucleotide information related to rpoE/hrpL of E. mallotivora was obtained from our previous RNA-seq experiment [20] and the full-length coding DNA sequence (CDS) of the EmhrpL gene was determined using the NCBI Open Reading Frame (ORF) finder (https://www.ncbi.nlm.nih.gov/ orffinder/). The hrpL CDS of E. mallotivora was then deposited at GenBank (https://www.ncbi.nlm.nih. gov/genbank/) under accession number MK205448. The E. mallotivora draft genome data (GenBank accession no.: JFHN01000044) reported by Ahmad-Redzuan et al. [18] were also utilised to validate the sequence of EmhrpL.

\subsection{Sequence Analysis, Gene Characterisation, and Phylogenetic Inferring of EmhrpL Gene}

The CDS was searched against the database in the BLASTn program (https://blast.ncbi.nlm.nih. gov/Blast.cgi) and a total of $18 \mathrm{hrpL} / \mathrm{rpoE}$ sequences from different Gram-negative bacteria were obtained. 
These sequences were aligned using Clustal W (BioEdit, Raleigh, NC, USA) and the phylogenetic tree (Maximum Likelihood) was inferred using MEGA7 software (Pennsylvania State University, University Park, PA, USA) with the bootstrap value set to 1000. The percentage of trees in which the associated taxa clustered together is depicted next to the branches. The initial tree for the heuristic search was obtained automatically by applying Neighbor-Join and BioNJ algorithms to a matrix of pairwise distances estimated using the Maximum Composite Likelihood (MCL) approach and then, selecting the topology with superior log likelihood value.

The ExPASy translate tool (SIB Bioinformatics Resource Portal, Lausanne, Switzerland) was employed to translate EmhrpL nucleotide to its amino acids and protein homology analysis was done using the Protein Fold Recognition Server (Phyre2, London, UK). The Pfam database (http: //pfam.xfam.org) and NPS@ server (https://npsa-prabi.ibcp.fr) were employed to study important protein motifs and domains on EmHrpL. The amino acid sequence was submitted to PSORTb version 3.0.2 (https://www.psort.org/psortb/) for the prediction of protein localisation.

\subsection{Molecular Docking Analysis of EmHrpL with an Anti- $\sigma$ Factor}

Molecular docking of EmHrpL with anti- $\sigma$ factor RseA of Escherichia coli was conducted using ZDOCK online server version 3.0.2 (http://zdock.umassmed.edu/). The structure of EmHrpL was predicted by SWISS-MODEL (https://swissmodel.expasy.org/) and deposited with repository number A0A014MCI7 using the crystal structure of RNA polymerase sigma-E factor (PDB ID: 1OR7) chain A as a template, with $25.31 \%$ sequence identity and 33\% sequence similarity. The resulting EmHrpL model was docked with the anti- $\sigma$ factor RseA, represented by chain C of the 1OR7 structure, including hydrogen bond interactions and salt bridge formations from 1OR7 as the contacting residues. Contact filtering had removed 1986 predictions out of 2000 from ZDOCK output files. EmHrpL was set as stationary and 1OR7_C was set to move.

\subsection{Competent Cell Preparation, Construct Development, and Mutagenesis and Mutant Selection}

Erwinia mallotivora with mutated $h r p L$ gene $(\triangle E m h r p L)$ was developed using the TargeTron ${ }^{\circledR}$ Gene Knockout System (Sigma-Aldrich, St. Louis, MO, USA) according to the manufacturer's protocol. The knockout system is a mutagenesis system based on the group II intron of the ltrB gene of Lactobacillus lactis. First, identification of the Lltr group II intron site within the EmhrpL ORF was carried out using an algorithm accessible from the Sigma-Aldrich TargeTron ${ }^{\circledR}$ website (www.sigmaaldrich.com/targetronaccess), and sets of unique primers were exclusively generated by the program (Figure 1a). These primers were synthesised and utilised to generate a PCR fragment $(350 \mathrm{bp}$ ) through overlap PCR reaction (1-step assembly PCR) that later was used in the development of a functional cassette for $h r p L$-targeted gene reverse splicing (Figure 1b). This generated a PCR fragment (retargeted intron) with HindIII and BsrGI restriction sites at the $5^{\prime}$ and $3^{\prime}$ UTR region, which was cloned into an intermediate plasmid. The plasmid was then digested with HindIII and BsrGI restriction enzymes and subcloned into a pACD4K-C linear vector to form a final construct ( $\mathrm{p} \Delta h r p L$ ) that would be ultimately used for generating the $\triangle E m h r p L$ strain. Competent cells of the E. coli DH5 $\alpha$ strain were transformed with the $\mathrm{p} \Delta h r p L$ plasmid and selected (for propagation) on LB agar plates containing $25 \mu \mathrm{g} / \mathrm{mL}$ of chloramphenicol. Purification and retrieval of all plasmid DNAs were carried out using a NucleoBond plasmid extraction kit (Macherey-Nagel GmbH \& Co., Doren, Germany).

Prior to transforming E. mallotivora with any plasmids, electrochemically competent cells were prepared. To produce competent E. mallotivora cells, the bacteria were cultured at $37^{\circ} \mathrm{C}$ until attaining an optical density of 0.8 at $600 \mathrm{~nm}$. Then, the cells were harvested by centrifugation at $12,000 \times g$ for $2 \mathrm{~min}$ and washed three times with $0.5 \mathrm{M}$ sucrose and finally, suspended in $0.5 \mathrm{M}$ sucrose. Plasmids of interest were transformed into the competent cells via electroporation using Bio-Rad micropulser (Bio-Rad) at $2.5 \mathrm{kV}$ and transformed cells underwent selection on chocolate LB agar containing an appropriate antibiotic. 
a Unique primers generated by TargeTron computer algorithm

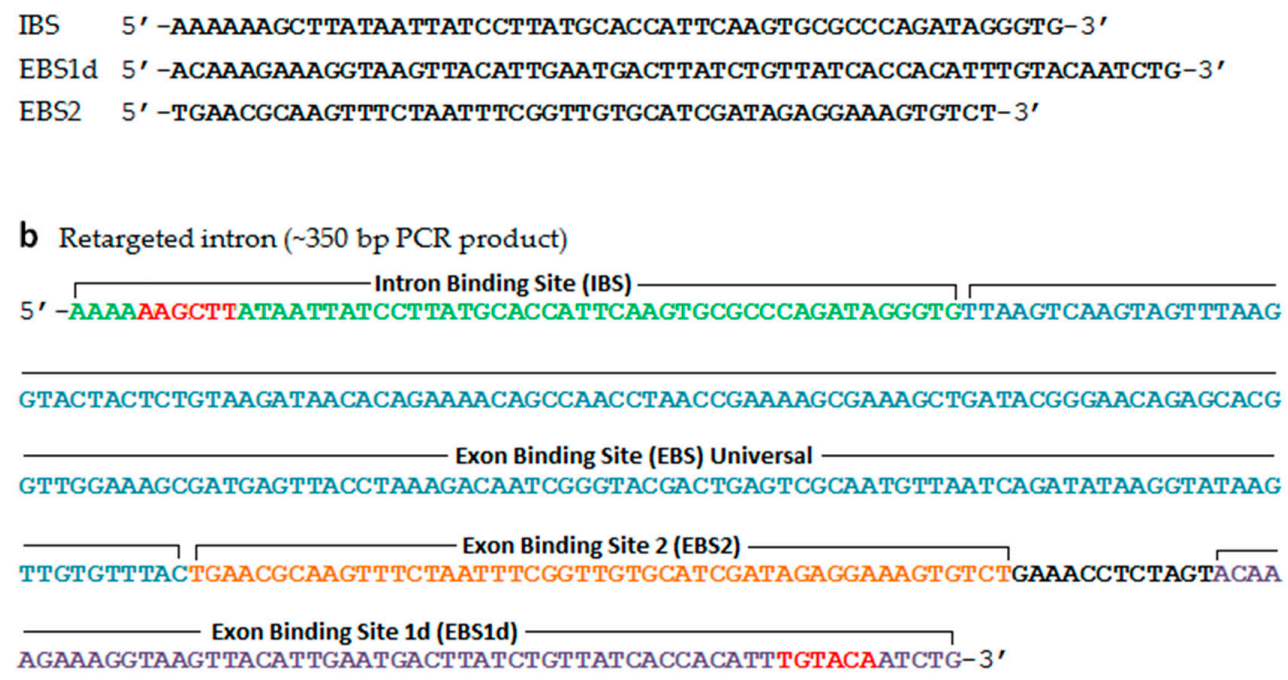

Figure 1. Sequences of Targetron ${ }^{\circledR}$ unique primers and retargeted intron. (a) Unique primers were generated by TargeTron ${ }^{\circledR}$ algorithm (www.sigmaaldrich.com/targetronaccess) and used to produce retargeted intron for gene reverse splicing; (b) Sequence of the retargeted intron ( $350 \mathrm{bp}$ ) containing HindIII (AAGCTT) and BsrGI (TGTACA) restriction sites generated by the three unique primers through 1-step assembly PCR.

As the TargeTron ${ }^{\circledR}$ system plasmid requires the use of a T7 promoter for targeting and mutation of selected genes in the bacterium of interest, E. mallotivora was first transformed with pAR1219, a pBR322-based vector, which expresses T7 RNA Polymerase under the control of the IPTG inducible lac UV5 promoter. At this first step, the E. mallotivora-pAR1219 strain was produced. This was to provide T7 RNA polymerase for the TargeTron ${ }^{\circledR}$ system to function once delivered into the bacterial cell. In the second step, the E. mallotivora-pAR1219 strain was transformed again with $\mathrm{p} \Delta h r p L$ to generate putative mutants. Putative mutants were detectable after 48 hours (temperature $=28{ }^{\circ} \mathrm{C}$ ) of selection on LB agar supplemented with kanamycin $(50 \mu \mathrm{g} / \mathrm{mL})$. To confirm intron insertion into the $h r p L$, PCR was conducted on putative mutant genomic DNA using combinations of gene- and intron-specific primers followed by DNA sequencing. All PCR conditions were as follows: initial pre-denaturation at $94{ }^{\circ} \mathrm{C}$ for $2 \mathrm{~min}$ followed by 35 cycles of denaturation at $94{ }^{\circ} \mathrm{C}$ for $30 \mathrm{~s}$, annealing at $52{ }^{\circ} \mathrm{C}$ for $30 \mathrm{~s}$, and extension at $72{ }^{\circ} \mathrm{C}$ for $2 \mathrm{~min}$.

\subsection{Pathogenesis Assay of the Mutant Strain}

Four-month-old plants of Carica papaya cv. Eksotika I were supplied by the Malaysian Agricultural Research and Development Institute (MARDI) Pontian, Johor. The plants were grown in a greenhouse under standard tropical conditions, where they received $13 \mathrm{~h}$ of light a day. Fresh colonies of the wild type and knockout mutant $\triangle E m h r p L$ strains of E. mallotivora were cultured overnight in LB broth (one colony in $50 \mathrm{~mL}$ broth) and incubated (with shaking at $150 \mathrm{RPM}$ ) at $28{ }^{\circ} \mathrm{C}$ until they reached $\mathrm{OD}_{600}=1.0$. Artificial wounding (by pricking) of the three lowermost papaya leaves was carried out using sterile needles and about five $\mathrm{mL}$ of E. mallotivora mutant/wild-type culture (resuspended in $1 \times$ phosphate-buffered saline) was sprayed to the plant part $\sim 15 \mathrm{~cm}$ from the shoot. Plants sprayed with $1 \times$ phosphate-buffered saline without E. mallotivora served as negative controls and all inoculated/sprayed plants were done in triplicates. The scorings were accomplished between 3-30 days post-inoculation (DPI).

Disease severity was scored following the study conducted by Juri et al. [21]. Disease severity scoring was evaluated using a 5-stage scale as follows: 0 -symptomless; 1 -leaf vein blackening; 2-leaf vein blackening + slight wilting; 3-leaf stalk wilting; 4-stem blackening; 5-plant death. 


\section{Results}

\subsection{Sequence Characterisation of EmhrpL Gene and Its Product, HrpL}

The full EmhrpL CDS was deposited to GenBank under the accession number MK205448. The CDS was $549 \mathrm{bp}$ long and encoded 182 amino acids. Its start codon did not follow the Kozak consensus sequence pattern (ATGG), confirming the hrpL belongs to a non-eukaryotic organism (Figure 2a). The calculated molecular weight (MW) of the deduced amino acid was 21,295.03 Da (21.3 kDa), and it had an overall isoelectric point (IP) of 6.19, indicating the gene product belongs to the $\sigma^{24}$ protein group and is slightly acidic. A sequence search of EmhrpL against the NCBI database revealed high sequence similarity of the protein to other alternative $\sigma$ factors from 18 bacterium species (Table 1) and phylogenetic inference based on those hrpL/rpoE sequences (Figure 3) indicated E. mallotivora was clustered together with E. tracheiphila and Pantoea vagans-pathogens that cause bacterial diseases in cucurbits and eucalyptus, respectively [22,23].

(a)

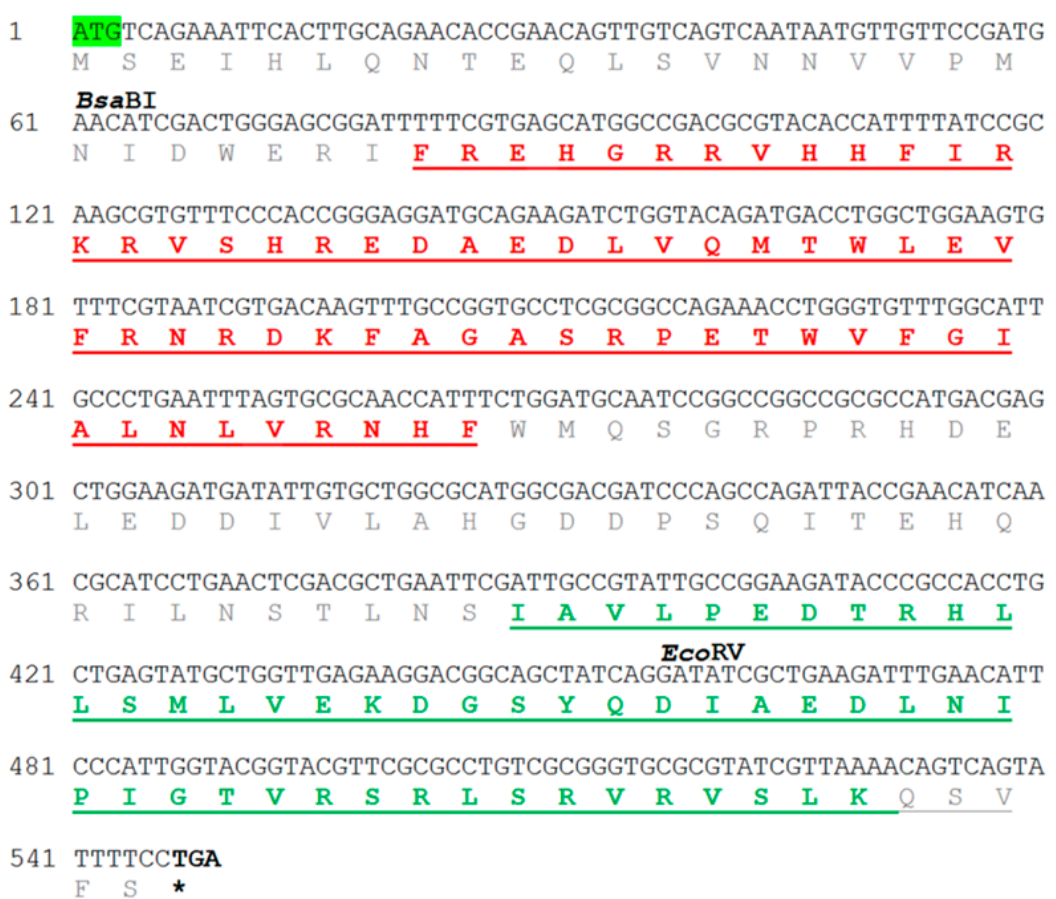

(b)

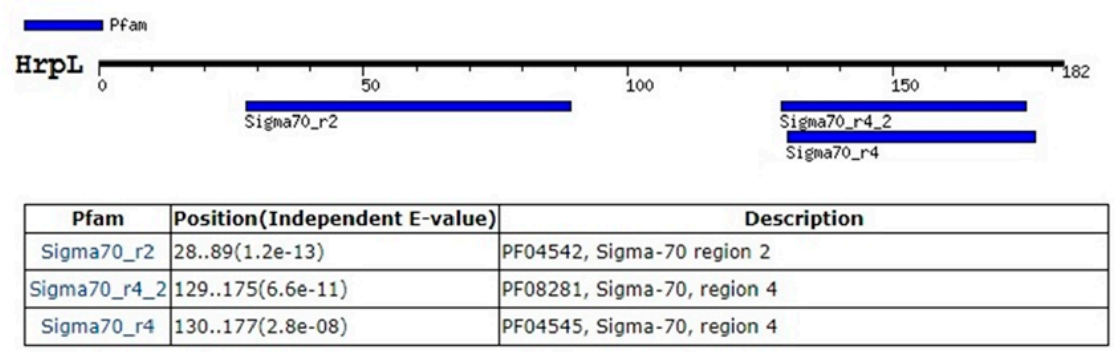

Figure 2. Cont. 
(c)

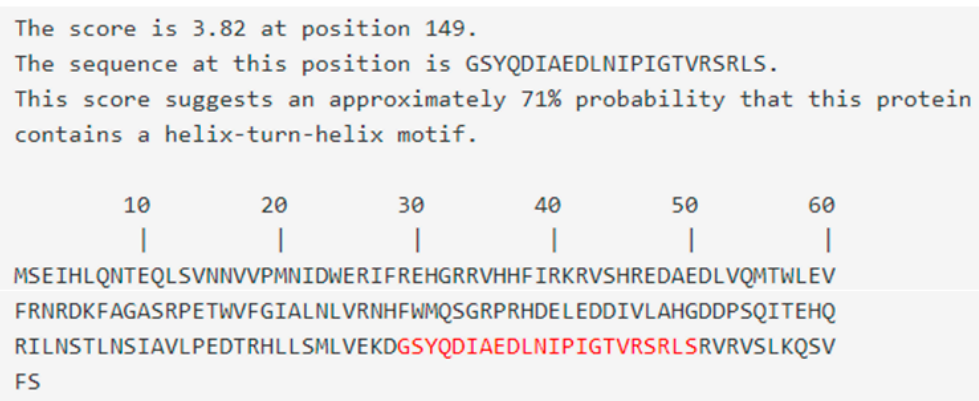

Figure 2. Sequence analysis of Emhrpl open reading frame (ORF) and motif finding on its translated protein. (a) Nucleotide sequence of EmhrpL (MK205448) and its deduced amino acids. The nucleotide sequences for $B s a \mathrm{BI}$ and $E c o R V$ restriction sites are as indicated and the two conserved $\sigma$ factor motifs on the amino acids, region R2 (red letters) and region R4 (green letters), are underlined. (b) Motif search on GenomeNet detected only two $\sigma$ regions (or motifs) on EmHrpL, indicating the $\sigma$ protein belongs to Group IV factor while (c) NPS@ server identified an HTH motif at position 149 of the amino acid (letters in red) corresponding to $\sigma \mathrm{R} 4$ of the EmHrpL. $\left({ }^{*}=\right.$ termination of translation by the stop codon TGA).

The GenomeNet motif search tool (Pfam database, https://pfam.xfam.org/) revealed EmHrpL harboured two highly conserved $\sigma$ regions $-\sigma R 2$ and $\sigma R 4$ (Figure 3). Based on the amino acid sequence alignment on six closely related RpoEs/sigmas/HrpLs (Figure 4), $\sigma \mathrm{R} 2$ and $\sigma \mathrm{R} 4$ of EmHrpL were highly conserved and their calculated PIs were 11.11 and 6.78, respectively. Additionally, $\sigma R 4$ was verified using the Pfam database and NPS@ server to have the helix-turn-helix (HTH) DNA binding motif (Figure 2b,c). Protein localisation analysis through PSORTb v3.0.2 predicted EmHrpL was a cytoplasmic protein (Table 2) and this result is consistent with the $\sigma$ factor RpoE from E. coli $[24,25]$.

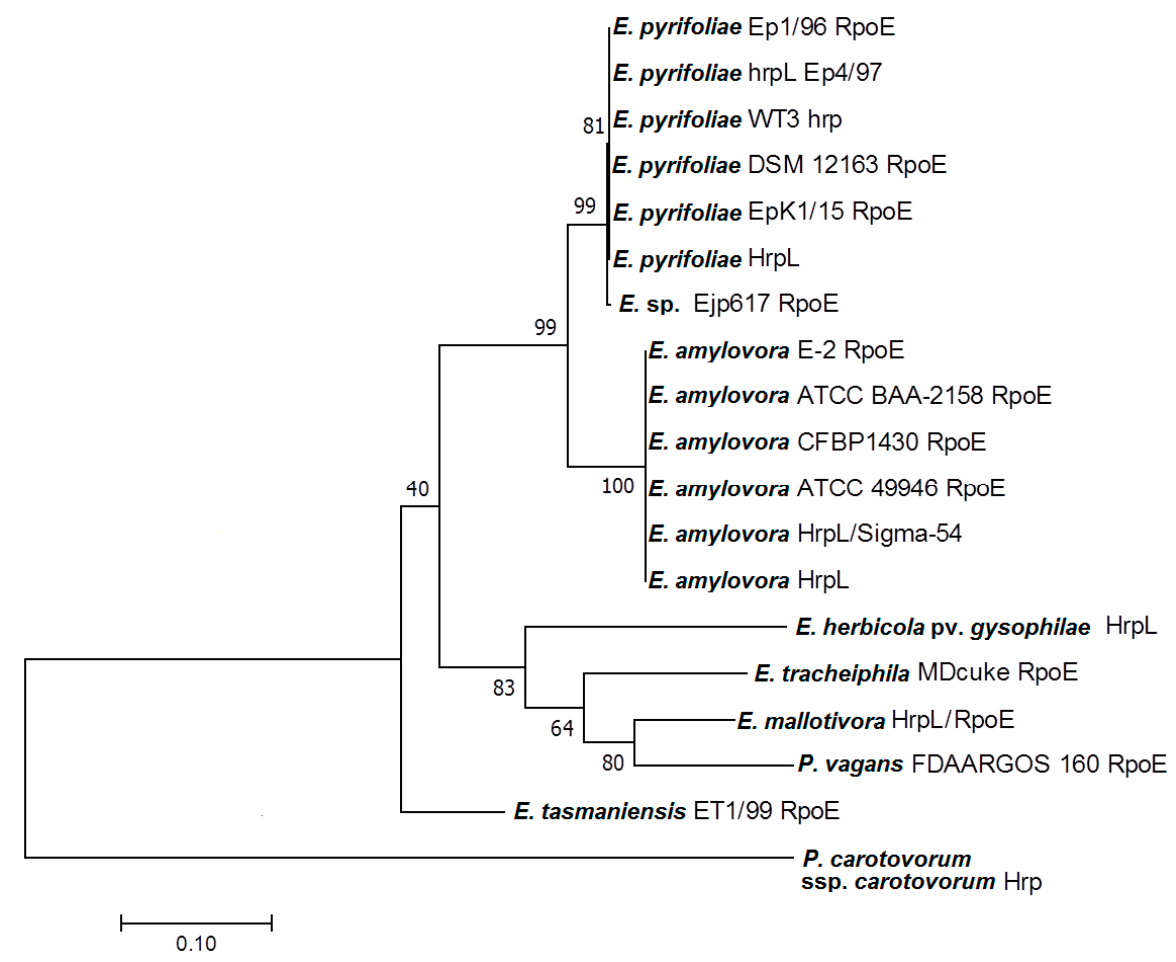

Figure 3. Molecular phylogenetic analysis of $h r p L$ from E. mallotivora (Accession no. MK205448) and $h r p L / r p o E$ gene sequences from related taxa by Maximum Likelihood (ML) method. A total of 18 nucleotide sequences were obtained from NCBI to construct the phylogenetic tree of sigma factors, and Pseudomonas carotovorum ssp. carotovorum served as an outgroup. The evolutionary history was inferred by using the ML method based on the Tamura-Nei model. The tree with the highest log likelihood (-2872.15) is shown. 
Table 1. Summary of BLASTn results based on the EmhrpL sequence (Accession no. MK205448).

\begin{tabular}{ccccccc}
\hline Description & $\begin{array}{c}\text { Max } \\
\text { Score }\end{array}$ & $\begin{array}{c}\text { Total } \\
\text { Score }\end{array}$ & $\begin{array}{c}\text { Query } \\
\text { Cover }\end{array}$ & E Value & Identity & Accession \\
\hline Pantoe vagans FDAARGOS 160 & 598 & 598 & $97 \%$ & $8 \times 10^{-167}$ & $85 \%$ & CP014128.2 \\
Erwinia tracheiphila MDcuke & 576 & 576 & $100 \%$ & $3 \times 10^{-160}$ & $83 \%$ & CP013970.1 \\
Erwinia sp. Ejp617, & 519 & 519 & $99 \%$ & $6 \times 10^{-143}$ & $81 \%$ & CP002124.1 \\
E. pyrifoliae EpK1/15 & 510 & 510 & $99 \%$ & $3 \times 10^{-140}$ & $81 \%$ & CP023567.1 \\
E. pyrifoliae DSM 12163 & 510 & 510 & $99 \%$ & $3 \times 10^{-140}$ & $81 \%$ & FN392235.1 \\
E. pyrifoliae WT3 & 510 & 510 & $99 \%$ & $3 \times 10^{-140}$ & $81 \%$ & DQ180962.2 \\
E. pyrifoliae Ep1/96 & 510 & 510 & $99 \%$ & $3 \times 10^{-140}$ & $81 \%$ & FP236842.1 \\
E. pyrifoliae & 510 & 510 & $99 \%$ & $3 \times 10^{-140}$ & $81 \%$ & AY532654.1 \\
E. pyrifoliae Ep4/97 & 510 & 510 & $99 \%$ & $3 \times 10^{-140}$ & $81 \%$ & AJ438881.1 \\
E. tasmaniensis ET1/99 & 488 & 488 & $99 \%$ & $1 \times 10^{-133}$ & $80 \%$ & CU468135.1 \\
E. amylovora E-2 & 465 & 465 & $99 \%$ & $1 \times 10^{-126}$ & $79 \%$ & CP024970.1 \\
E. amylovora ATCC BAA-2158 & 465 & 465 & $99 \%$ & $1 \times 10^{-126}$ & $79 \%$ & FR719186.1 \\
E. amylovora CFBP1430 & 465 & 465 & $99 \%$ & $1 \times 10^{-126}$ & $79 \%$ & FN434113.1 \\
E. amylovora ATCC 49946 & 465 & 465 & $99 \%$ & $1 \times 10^{-126}$ & $79 \%$ & FN666575.1 \\
E. amylovora & 465 & 465 & $99 \%$ & $1 \times 10^{-126}$ & $79 \%$ & AF083877.1 \\
E. amylovora & 465 & 465 & $99 \%$ & $1 \times 10^{-126}$ & $79 \%$ & U36244.1 \\
E. herbicola pv. gypsophilae & 445 & 445 & $100 \%$ & $1 \times 10^{-120}$ & $78 \%$ & AF272053.1 \\
Pseudomonas carotovorum ssp. carotovorum & 109 & 109 & $73 \%$ & $1 \times 10^{-19}$ & $67 \%$ & EU420066.1 \\
\hline
\end{tabular}

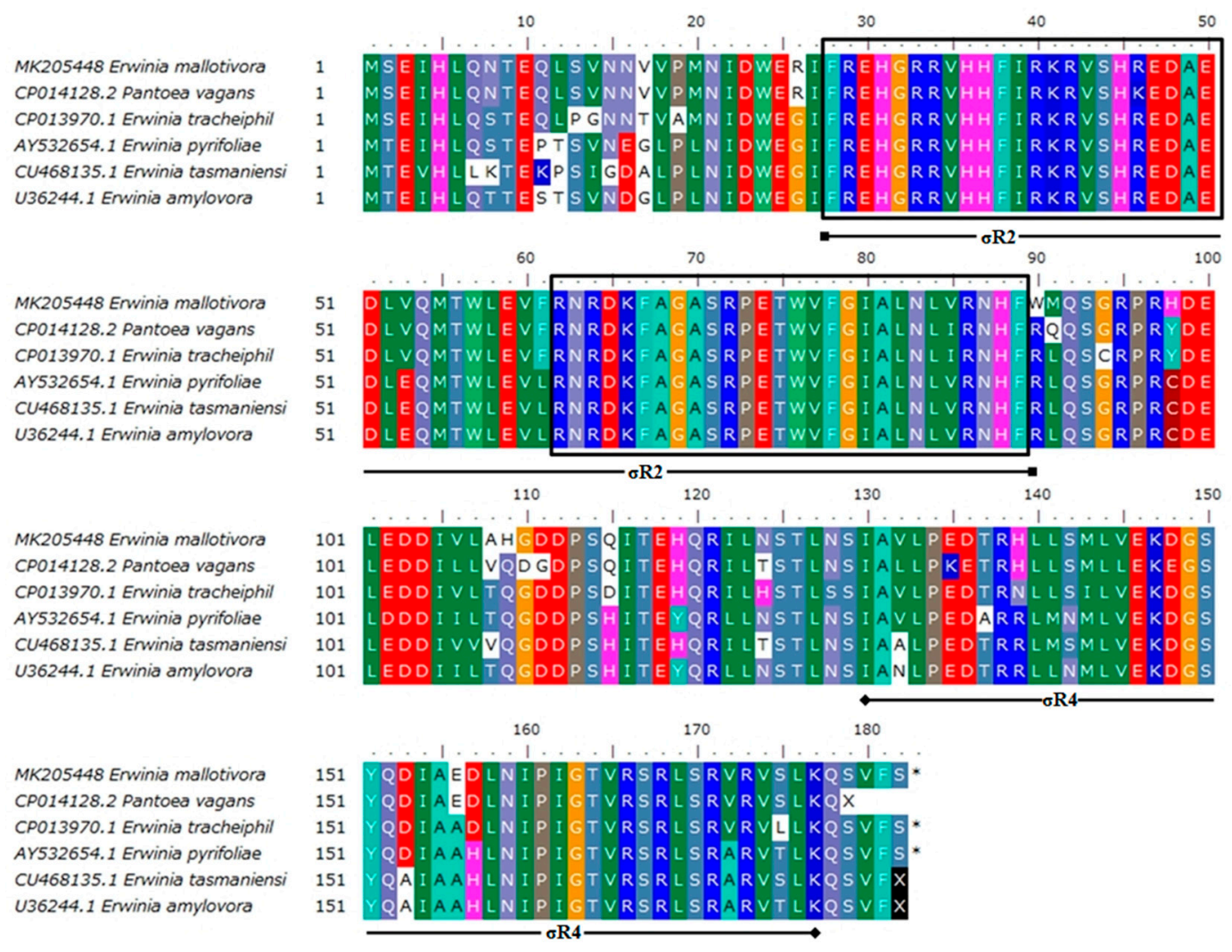

Figure 4. Multiple sequence alignment of deduced amino acids of E. mallotivora hrpL (MK205448), Pantoea vagans rpoE (CP014128.2), E. tracheiphila rpoE (CP013970.1), E. pyrifoliae hrpL (AY532654.1), E. tasmaniensis rpoE (CU468135.1), and E. amylovora hrpL (U36244.1). Boxed are the extremely conserved sequences located on $\sigma \mathrm{R} 2$ regions from six different bacterium species. 
Table 2. Tabulated result on prediction of subcellular localisation of HrpL using PSORTb v3.0.2 Bacterial Localisation Prediction Tool.

\begin{tabular}{ccc}
\hline \multicolumn{2}{c}{ Seq ID: MK205448.1 } \\
\hline \multicolumn{1}{c}{ Erwinia mallotivora } & strain BT-MARDI RNA Polymerase Sigma Factor RpoE/hrpL \\
\hline Analysis Report & & Details \\
Analytical Modules & Prediction & - \\
CMSVM & Unknown & - \\
CytoSVM & Cytoplasmic & Matched 16130498: RNA polymerase, sigma 24 (sigma E) \\
SCL-BLAST & Cytoplasmic & - \\
SCL-BLAST & fnknown & - \\
Signal & Unknown & \\
Localisation & Scores & \\
Cytoplasmic & 9.97 & \\
Cytoplasmic Membrane & 0.01 & \\
Periplasmic & 0.01 & \\
Outer membrane & 0.00 & \\
Extracellular & 0.00 & \\
\hline Final Prediction & & \\
Cytoplasmic & 9.97 & \\
\hline
\end{tabular}

\subsection{Homology of EmHrpL}

To further investigate the protein conformation of EmHrpL, a series of in silico tools were employed to generate a 3D structure. The Phyre2 protein fold recognition server had generated a list of homologous proteins based on the submitted amino acid sequence, and the top four models are tabulated in Table 3. Template c1or7A_ (based on the crystal structure of E. coli sigma factor E) was selected for EmHrpL structure analysis for having the best identity percentage and $100 \%$ confidence. The c1or7A_PDB file was then reconstructed using Phyton Molecular Viewer (PMV 1.5.6, Schrödinger Inc., New York, NY, USA) to visualise the 3D protein structure as in Figure 5. The generated $\sigma$ $3 \mathrm{D}$ model comprised a conserved $\sigma$ region $2(\sigma \mathrm{R} 2)$ as the N-terminal domain and a conserved $\sigma \mathrm{R} 4$ domain as the C-terminal domain. These two regions, or domains, were connected by a $\sigma$ linker, and this conformation was very similar to the crystal protein structure of $E$. coli RpoE reported by Campbell et al. [26]. In accordance with the previous amino acid sequence analyses, a helix-turn-helix $(\mathrm{HTH})$ motif that mediates $\sigma$ factor interaction with the -35 element in the promoter region and a cognate anti- $\sigma$ factor can be visualised from the $\sigma \mathrm{R} 4$ domain of the EmHrpL 3D structure.

Table 3. Homology modelling of EmhrpL from top four models (100\% confidence). Primary amino acids sequence of EmhrpL was submitted to Phyre2 and targeted with sigma factors available on PDB.

\begin{tabular}{|c|c|c|c|c|}
\hline Template & $\begin{array}{l}\text { Alignment } \\
\text { Coverage }\end{array}$ & Confidence & $\begin{array}{c}\% \\
\text { Identity }\end{array}$ & Template Formation \\
\hline c1or7A_ & $\begin{array}{l}8-181 \\
(95 \%)\end{array}$ & 100 & 23 & $\begin{array}{l}\text { PDB header: transcription } \\
\text { Chain: A: PDB Molecule: RNA polymerase sigmaE factor; } \\
\text { PDB Title: crystal structure of Escherichia coli sigmaE with the } \\
\text { cytoplasmic domain of its anti-sigma RseA }\end{array}$ \\
\hline c4cxfA_ & $\begin{array}{l}7-182 \\
(96 \%)\end{array}$ & 100 & 20 & $\begin{array}{c}\text { PDB header: transcription } \\
\text { Chain: A: PDB Molecule: RNA polymerase sigma factor } \mathrm{CnrH} \text {; } \\
\text { PDB Title: structure of CnrH in complex with the cytosolic } \\
\text { domain of CnrY }\end{array}$ \\
\hline c5wurB & $\begin{array}{l}7-181 \\
(95 \%)\end{array}$ & 100 & 23 & $\begin{array}{l}\text { PDB header: metal-binding protein } \\
\text { Chain: B: PDB Molecule: ECF RNA polymerase sigma factor } \\
\text { SigW; PDB Title: crystal structure of SigW in complex with its } \\
\text { anti-sigma RsiW, an oxidised form }\end{array}$ \\
\hline c2q1zA_ & $\begin{array}{l}5-180 \\
(96 \%)\end{array}$ & 100 & 18 & $\begin{array}{c}\text { PDB header: transcription } \\
\text { Chain: A: PDB Molecule: RpoE, ECF SigE; } \\
\text { PDB Title: crystal structure of Rhodobacter sphaeroides SigE in } \\
\text { complex with the anti-sigma ChrR }\end{array}$ \\
\hline
\end{tabular}




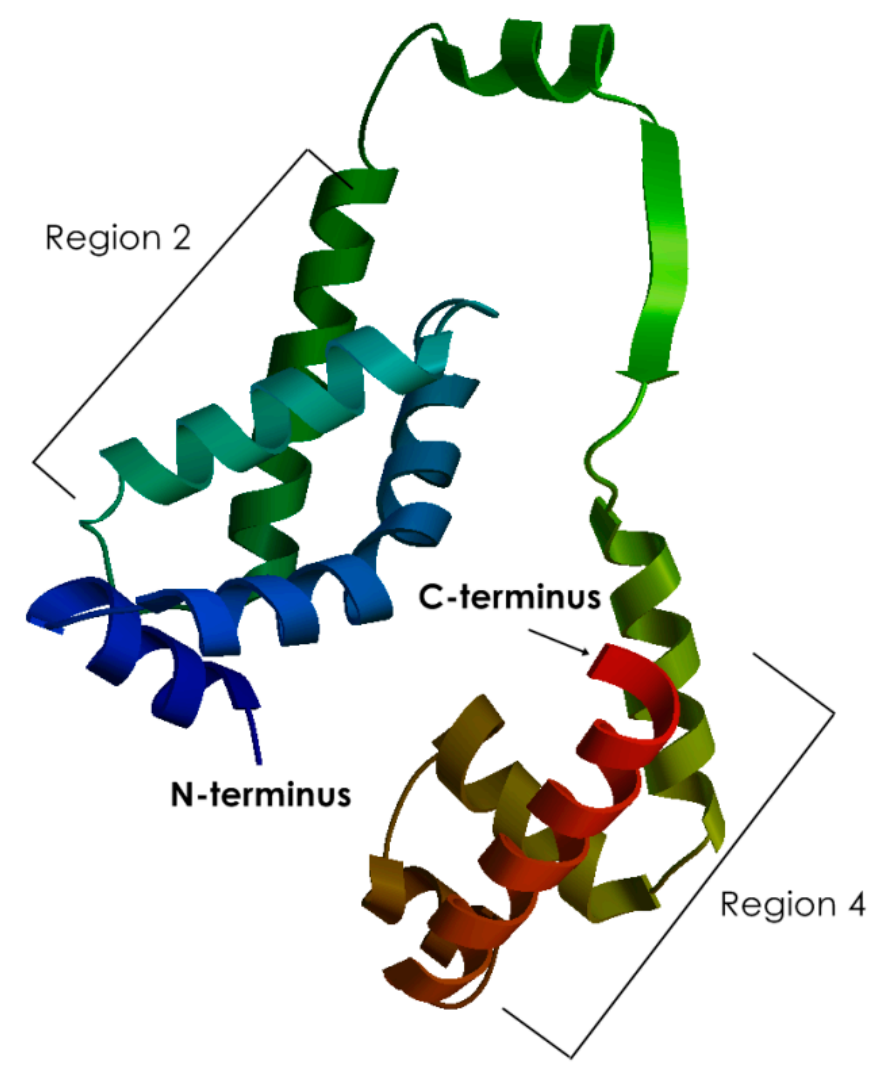

Figure 5. Predicted 3D structure of E. mallotivora's $\sigma$ factor ( $100 \%$ confidence) based on homology modelling of E. coli sigma factor E (RpoE) crystal structure. The region $4(\sigma R 4)$ structure possesses the helix-turn-helix (HTH) motif as visualised.

3.3. Prediction of a Potential Inhibitor and Its Binding Affinity (Kd) with EmHrpL through PPI In Silico Analysis

As stated, E. mallotivora HrpL protein shared conserved motifs with the E. coli $\sigma^{\mathrm{E}}$ (or RpoE); hence, the molecular docking technique was employed to assess the probability of E. mallotivora HrpL forming a complex with the E. coli anti- $\sigma$ factor RseA. A molecular docking simulation was conducted using ZDOCK online server version 3.0.2 to investigate the protein-protein interaction (PPI) of the two $\sigma$ factors with the said inhibitor, and the generated results are revealed in Figure 6. The highest ZDOCK score for the EmHrpL:RseA complex was 1312.338, and the 1OR7 (RpoE:RseA) complex was also re-docked to compare its score, which was 3316.534, 40\% higher than EmHrpL:RseA score. A higher docking score means better interaction affinity when analysed using ZDOCK. The total interface area of the EmHrpL:RseA complex was $5223.3 \AA^{2}$ with gap volume $6945.75 \AA^{3}$ forming eight hydrogen bonds and seven salt bridges. On the other hand, the 1OR7 (RpoE:RseA) complex had a total interface area of $5715.3 \AA^{2}$ with gap volume $4522.50 \AA^{3}$ forming 16 hydrogen bonds and seven salt bridges in between. Based on these figures, the interface areas $\left(\AA^{2}\right)$ in both protein complexes were not too different from each other ( 5715.3 vs. $5223.3 \AA^{2}$ ), and this indicated that the total contact area between the RseA with HrpL is very similar to that produced by the 1OR7 complex. However, EmHrpL:RseA had a much higher gap volume $\left(\AA^{3}\right)$ and formed $50 \%$ less hydrogen bonds compared to 1OR7. Based on the ZDOCK score, interface areas, hydrogen bonds, and salt bridges, the binding affinity (Kd) for EmHrpL:RseA was estimated to be $0.8 \times 10^{-10} \mathrm{M}$, slightly less than half of what had been determined for the 1 OR7 complex, which was $2 \times 10^{-10} \mathrm{M}[26,27]$. 


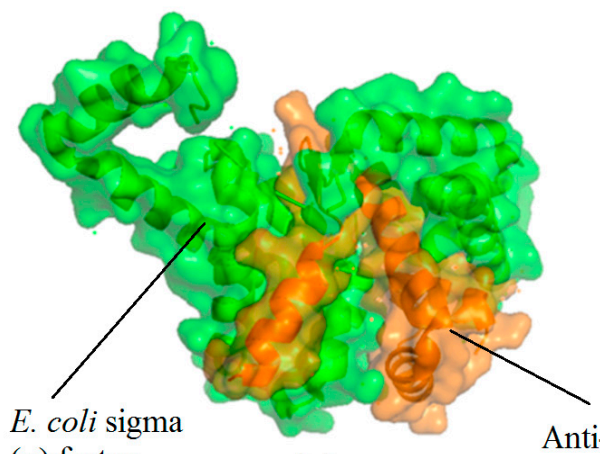

$(\sigma)$ factor RpoE (a)

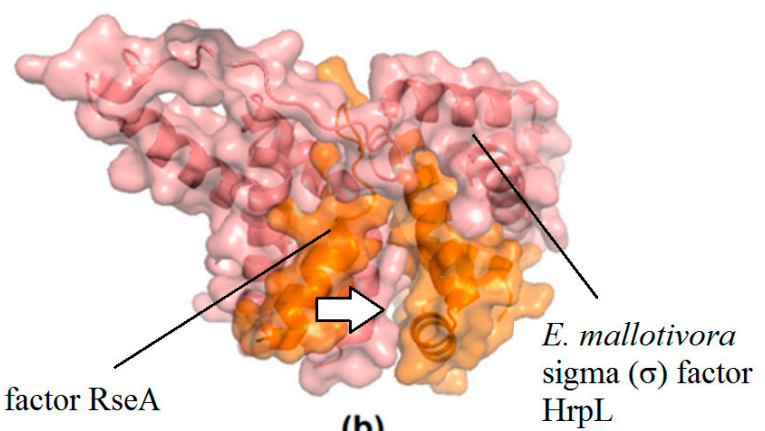

(b) HrpL

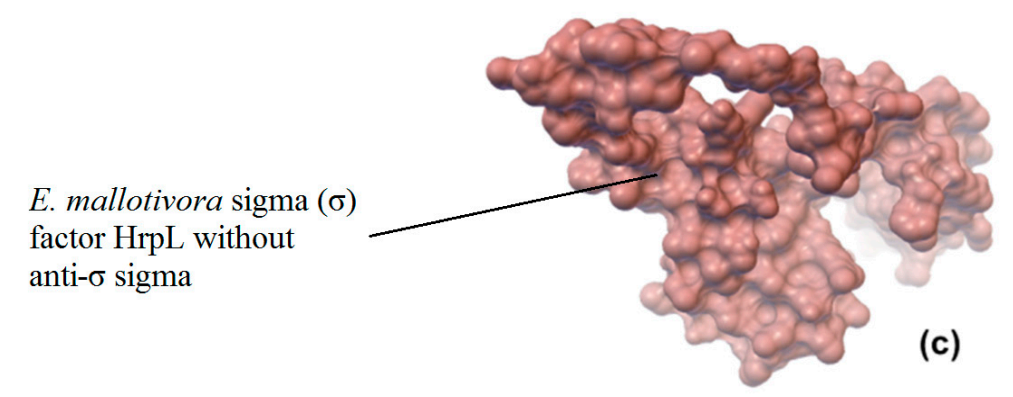

Figure 6. Protein-protein interaction (PPI) study of molecular docking using ZDOCK protein-docking server. Structure as with visible surface at $40 \%$ transparency and secondary structures edited in PyMOL. (a) E.coli RNA polymerase sigma-E factor chain A (green) forming a complex with anti- $\sigma$ factor RseA chain C (orange), and (b) EmHrpL (red) bound by anti- $\sigma$ factor RseA chain C (orange) with a visible gap between the two proteins (white arrow). (c) EmHrpL without the anti- $\sigma$ factor RseA viewed using PMV with a visible surface at $0 \%$ transparency.

According to Janin et al. [28] and Erijman et al. [29], an interface area of $\sim 1500 \AA^{2}$ with at least ten hydrogen bonds has enough enthalpy to generate a dissociation constant (Kd) of up to $10^{-14} \mathrm{M}(\mathrm{fM})$, and the smaller the $\mathrm{Kd}$, the higher the binding affinity between the two substances. Erijman et al. [29] conducted a comprehensive study on different levels of binding affinities on different PPIs based on several types of molecular features and concluded that PPIs can be classified as high $\left(\mathrm{Kd} \leq 10^{-9} \mathrm{M}\right)$, medium $\left(10^{-9} \mathrm{M}<\mathrm{Kd} \leq 10^{-6} \mathrm{M}\right)$, and low affinity $\left(\mathrm{Kd}>10^{-6} \mathrm{M}\right)$. As previously mentioned, 1OR7 has been determined to have $\mathrm{Kd}$ of $2 \times 10^{-10} \mathrm{M}$, which is in the high-affinity PPI category. Based on the PPI analysis and binding affinity levels produced by Erijman et al. [29], it is concluded that the binding affinity for EmHrpL:RseA $\left(0.8 \times 10^{-10} \mathrm{M}\right)$ is estimated to be in the high-affinity PPI, though having Kd slightly lower than that of 1 OR7.

\subsection{Targeted hrpL Disruption in E. mallotivora by Using a Group II Intron (TargeTron ${ }^{\circledR}$ ) System}

In order to further understand how hrpL determines E. mallotivora pathogenicity in papaya, functional characterisation of this T3SS regulator was conducted through loss-of-function mutagenesis, and a similar gene knockout experiment targeting a different gene was conducted by Juri et al. [20]. After transformation via electroporation, putative mutant colonies were first selected on LB agar containing kanamycin and subsequent PCR had validated the transformed cells containing the intron insertion based on the larger amplicon size ( 850 vs. 500 bp) (Figure 7b). Colony PCR was also conducted on E. mallotivora marker genes (E. mallotivora $h r p N$, isochorismate mutase, and $h r p S$ ) to validate the species authenticity of the $\triangle E m h r p L$ colonies (data not shown). In this study, the mutant E. mallotivora strain $(\triangle E m h r p L)$ was successfully generated (Figure 7a), though the number of retrieved colonies was very low. The steps were relatively meticulous since the bacteria needed to be transformed with two types of vectors, pAR1219 and $\mathrm{p} \Delta h r p L$ (pACD4K-C). 


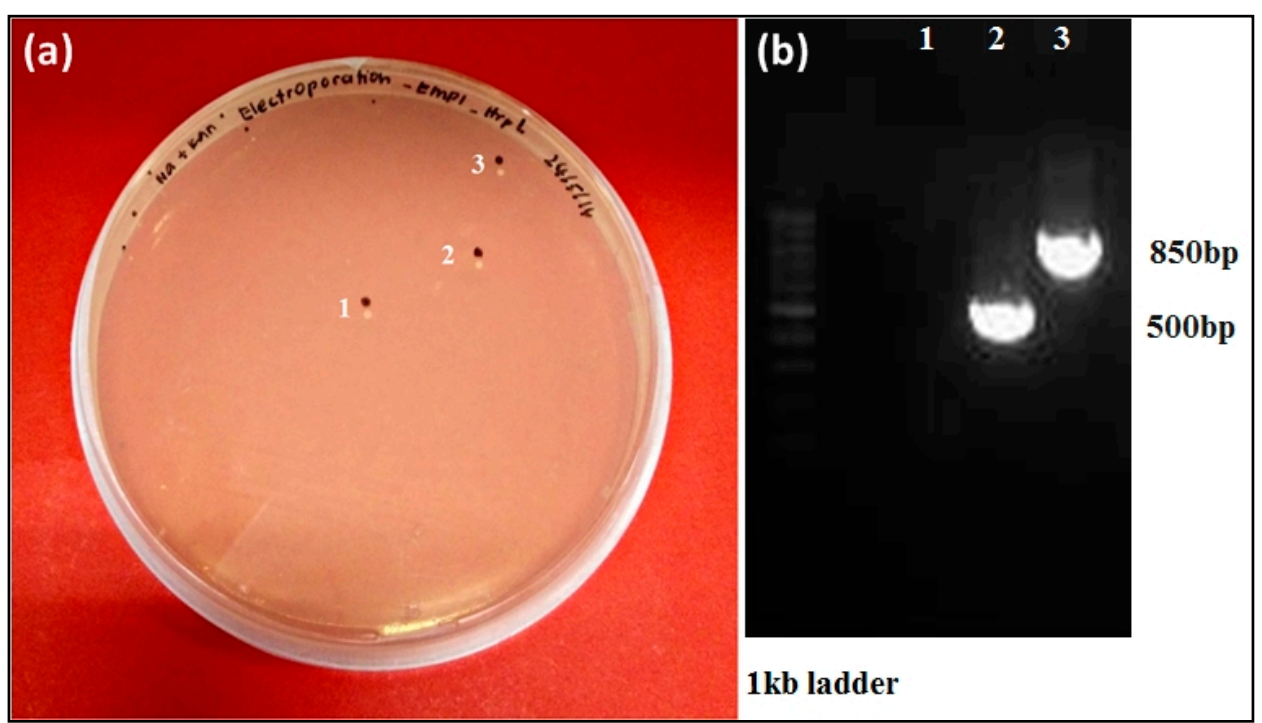

Figure 7. Antibiotic selection of transformed E. mallotivora cells and confirmation of hrpL disruption in the genome by PCR. (a) Selection of putative mutants was carried out on LB agar supplemented with kanamycin $(50 \mu \mathrm{g} / \mathrm{mL})$. (b) For PCR validation, $h r p L$ gene-specific primers were used to validate the putative mutants obtained from the selection step. The mutated strain $(\triangle E m h r p L)$ has a larger gene size due to insertion by the intron (lane 3) compared to non-mutant/wild type (lane 2). Lane 1 served as negative control.

\subsection{Mutagenesis Study Revealed Involvement of hrpL in the Pathogenicity of E. mallotivora}

To investigate the involvement of hrpL in E. mallotivora pathogenicity, the $\Delta E m h r p L$ strain was used to artificially inoculate four-month-old papaya plants and the resulting disease severity was compared against severity produced by wild type E. mallotivora (positive control). The progression of dieback disease severity (averaged) on papaya plants caused by $\triangle E m h r p L$ vs. wild type strain is shown in Table 4 and it was based on the 0-5 papaya dieback disease severity score [21]. Upon infection with the $\Delta E m h r p L$ strain, the papaya plants manifested zero symptoms during 3-12 DPI. However, the veins of wounded leaves started to blacken (stage 1) on 16-20 DPI, indicating early entry of the mutant E. mallotivora through the wounds. However, beyond 25 DPI, the leaf vein blackening of wounded leaves diminished while the leaves slowly turned yellow (data not shown). On 30 DPI, the leaves previously presenting stage 1 symptoms were completely abscised from the stem and only unwounded leaves remained healthy and intact. At this stage, the disease severity score of these plants had reverted to stage 0 . Blackening of leaf veins (stage 1) was also observed in papaya plants infected with wild type E. mallotivora but it manifested as early as 3 DPI. The progression of disease severity continued from stage 2 through to stage 5 until 20 DPI, where the plants completely succumbed to the disease and were beyond cure. It was observed that the severity and intensity of the symptoms developed by plants sprayed with the mutant E. mallotivora strain, $\triangle E m h r p L$, was significantly lower than that of plants sprayed with parent/wild type E. mallotivora. 
Table 4. Summarised dieback disease severity scoring of papaya plants (in triplicates) after being sprayed/inoculated with wild type strain, $\triangle E m h r p L$, and negative control solution (Stage 0 -symptomless; Stage 1-leaf vein blackening; Stage 2-leaf vein blackening + slight wilting; Stage 3-leaf stalk wilting; Stage 4-stem blackening; Stage 5-plant death).

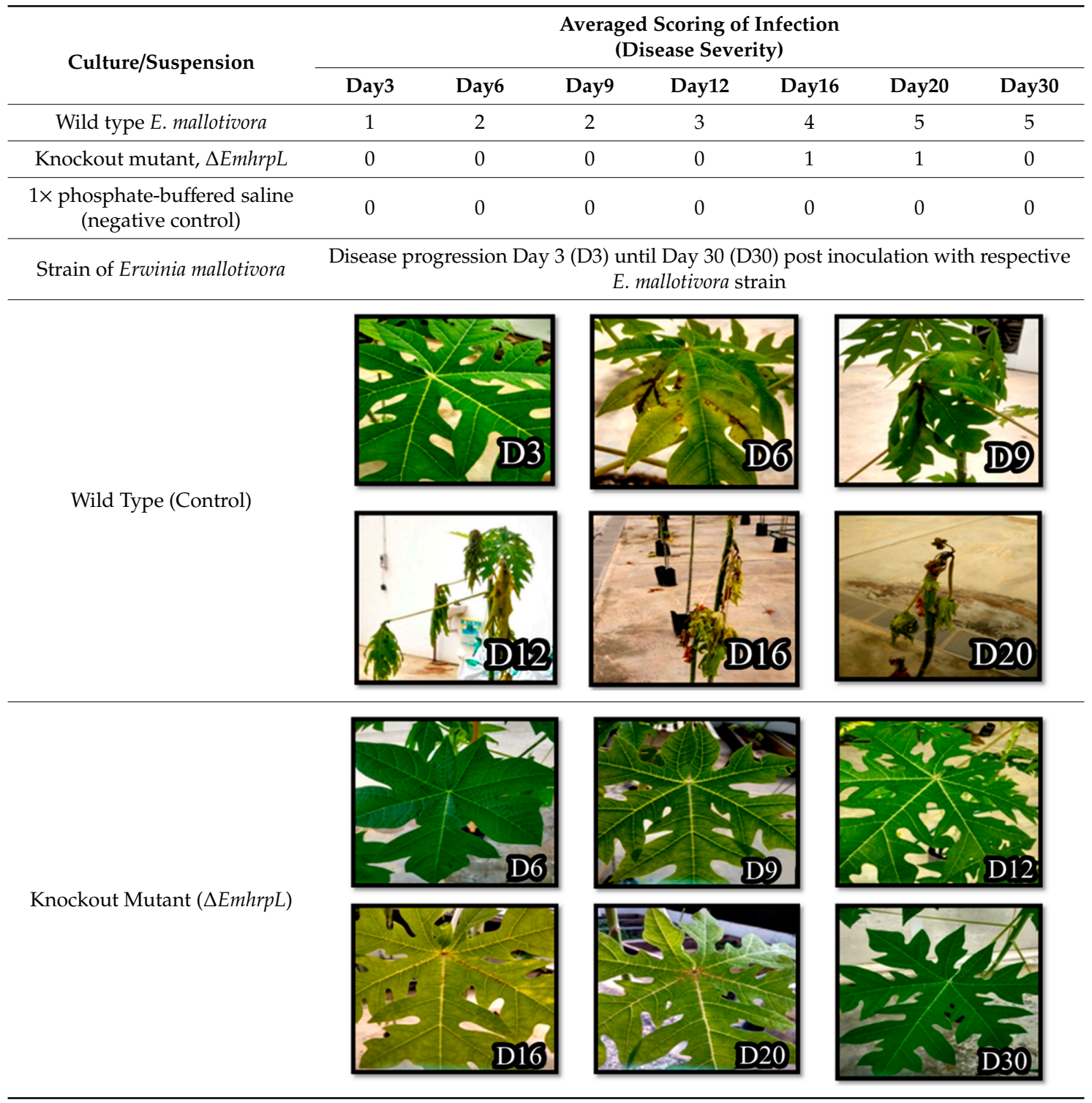

\section{Discussion}

The T3SS is highly conserved in Gram-negative bacteria and a comparative study on genes from related taxa is very useful in determining common biological features, especially on conserved functions. The importance of $h r p L$ and involvement of the T3SS in pathogenicity have been documented in other phytopathogenic bacteria [30,31]. Wei and Beer [13] reported the hrpL of E. amylovora is involved in the hrp signal transduction cascade during plant-pathogen interaction in the fire blight disease of rosaceous plants; thus, the hrpL from E. mallotivora should have a similar role in causing infection in papaya due to the conserved motifs identified from the nucleotide and amino acid sequences. In this study, the sequence analyses indicated E. mallotivora HrpL (EmHrpL) belongs to an extracytoplasmic function (ECF) protein family whose members are classified based on their generally smaller size and the presence of only two $\sigma$ regions $(\sigma \mathrm{R} 2$ and $\sigma \mathrm{R} 4)[32,33]$. The ECF proteins, as the name indicates, regulate gene expressions pertaining to stresses and pathogenesis upon detection of stimuli that come from the exterior of the cell cytoplasm $[2,13,34,35]$. The two highly conserved $\sigma \mathrm{R} 2$ and $\sigma \mathrm{R} 4$ regions 
that specified EmHrpL belong to a larger, primary sigma factor $\sigma^{70}$ family and the absence of $\sigma \mathrm{R} 1.1$ has confirmed that the protein belongs to Group IV $\sigma$ factor $[36,37]$. According to the literature, the two sigma regions ( $\sigma \mathrm{R} 2$ and $\sigma \mathrm{R} 4$ ) are crucial for RNA polymerase DNA-specific recognition during transcription initiation, where the $\sigma \mathrm{R} 2$ is responsible for -10 promoter recognition while $\sigma \mathrm{R} 4$ is involved in -35 promoter binding during RNA polymerase interaction with the gene promoters $[9,27,36,38,39]$. In addition, $\sigma \mathrm{R} 2$ and $\sigma \mathrm{R} 4$ are the sites pairing up with a cognate anti- $\sigma$ during inhibition, and this feature has gained the main interest in this study. According to Lonetto et al. [36], these two sigma $\mathrm{R} 2$ and R4 regions could be further divided into several subregions but these are not discussed in this article.

Jovanovic et al. [40] reported that regulatory factor $\mathrm{HrpV}$ is able to impose negative control on $h r p L$ gene expression in P. syringae - a Gram-negative bacterium related to Erwinia spp.- though not through a direct interaction. A transcriptomics study reported by Juri et al. [20] managed to identify a set of pathogenesis-related genes during the early hours of E. mallotivora infection and $h r p V$ was one of the differentially expressed genes (DEGs), but the correlation of this gene with other T3SS elements in E. mallotivora was not discussed. It was then decided to attend to a different element that has a more direct interaction with HrpL through the $\sigma \mathrm{R} 2$ and $\sigma \mathrm{R} 4$ sites. There has not been any report on HrpL $\sigma$ factor from Erwinia being directly regulated, or inhibited, by a cognate anti- $\sigma$-a type of negative regulator [41]. However, in E. coli, its $\sigma$ factor RpoE (homologous to HrpL) remains inactive and bound to a cognate anti- $\sigma$ factor, RseA, inside the cytoplasm until an extracytoplasmic stimulus triggers the release of RpoE [26]. It was also shown by Campbell et al. [26] and Tam et al. [27] that E. coli $\sigma^{\mathrm{E}}(\mathrm{RpoE})$ was strongly inhibited by the anti- $\sigma$ factor RseA with binding affinity (Kd) of $0.2 \mathrm{nM}$ $\left(2 \times 10^{-10} \mathrm{M}\right)$ through the formation of $\sigma^{\mathrm{E}}$ :RseA (or RpoE:RseA) complex (PDB ID: 1OR7). Generally, $\sigma$ factors are co-transcribed with a cognate negative regulator and remain inactive by forming the $\sigma$ : inhibitor complex. The $\sigma$ factors will only be released from the complex to become ECF proteins once they receive a stimulus from the environment [6,35]. Since the anti- $\sigma$ factor RseA is a small protein that originally serves to inactivate RpoE in E. coli, its potential as an inhibitory molecule to suppress T3SS in E. mallotivora is very appealing to research. Our previous studies on transcriptomics, proteomics, and the draft genome were not able to identify the cognate anti- $\sigma$ factor for EmHrpL [18-20]; hence, a bioinformatics simulation had to be run to predict the bipartite interaction of $E$. coli RseA with the $\sigma \mathrm{R} 2$ and $\sigma R 4$ regions on E. mallotivora HrpL. As produced by the PPI study, it was simulated that the binding affinity of RseA to EmHrpL is comparable to that of native complex RpoE:RseA; therefore, the anti- $\sigma$ factor RseA has the potential to be used as an inhibitor to suppress the T3SS pathway in E. mallotivora and could be incorporated for disease control approaches. In addition to this, Boldrin et al. [42] concretely proved the inhibitory interaction of Rv1222 (RseA) on the expression of $\sigma^{\mathrm{E}}$-dependent genes in Mycobacterium tuberculosis, and this aligns with our result on the docking simulation.

In the final part of the experiment, further investigation was performed for the involvement of EmhrpL in causing papaya dieback disease through a loss-of-function mutagenesis study using a type II intron system (TargeTron ${ }^{\circledR}$ ). As mentioned, it was observed $\Delta E m h r p L$ exhibited 'weakened' pathogenicity based on reduced symptoms in infected plants (stage 1) instead of complete nullification. Juri et al. [19] and Abu-Bakar et al. [20] reported T3SS was not the only means of pathogenesis in E. mallotivora; hence, hypersensitive response (HR) could still be observed, though it occurred much later and was less aggressive compared to the control set. The possibility of the type II intron insertion in $\triangle E m h r p L$ to be lost when the symptom appeared on 16 DPI is ruled out since this system has been tested to be stable [43]. A mutagenesis study was done on $M$. tuberculosis by disrupting the $\sigma^{\mathrm{E}}$ gene, and it was discovered that the mutant $M$. tuberculosis had a reduced lethality in mice [44], a finding that resonates with our current study. Thus, it is concluded that E. mallotivora highly depends on HrpL to cause disease in its host plant, C. papaya.

So far, E. mallotivora has been reported to infect Mallotus japonicus and Malaysian C. papaya cultivars [17,45], while other possible hosts are unknown. Based on the present study, it is evident that $h r p L$ plays a pivotal role in E. mallotivora pathogenesis. To date, there is no published study on 
the HrpL/RpoE interaction with an anti- $\sigma$ in plant pathogens and our work provides the preliminary evidence of such interaction in E. mallotivora.

\section{Conclusions}

In this study, the phylogenetic relationship of EmhrpL with other sigma factors across many Gram-negative pathogens has been inferred and they harbour much conserved motifs, signifying a unified function in the pathogen-related pathway. In silico structural properties of EmHrpL protein have been identified, and its possible interaction with an anti- $\sigma$ has been simulated through molecular docking analysis. Even though the cognate, or native, EmHrpL anti- $\sigma$ is yet to be determined, there is a conviction that $E m \mathrm{HrpL}$ is indeed regulated by one. Erwinia mallotivora hrpL's important role in causing papaya dieback disease has ultimately been confirmed in a mutagenesis study, and this information is consistent with results produced from other studies. The outcomes of this project, especially on the role of an anti- $\sigma$, have improved our understanding of a regulatory element related to pathogenesis in E. mallotivora.

Author Contributions: Conceptualisation, A.-A.T. and N.A.-B.; methodology, N.A.-B., A.-A.T. and A.-F.S.; software, L.R.; validation, N.A.-B.; formal analysis, A.-A.T. and N.A.-B.; investigation, A.-A.T., A.-F.S., and N.A.-B.; resources, N.A.-B. and L.R.; data curation, R.A.-R., L.R. and N.A.-B.; writing-original draft preparation, A.-A.T.; writing-review and editing, N.A.-B., A.-A.T. and R.A.-R.; visualisation, A.-A.T. and L.R.; supervision, N.A.-B. and A.-M.A.-M.; project administration, N.A.-B.; funding acquisition, N.A.-B. All authors have read and agreed to the published version of the manuscript.

Funding: This work was supported partly by Fundamental Research Grant Scheme (FRGS) FRGS/1/2015/ST03/MOA/02/1 from the Malaysian Ministry of High Education (MOHE) and MARDI Development Research Grant PRB405.

Acknowledgments: We would like to thank Noriha Mat Amin (Biotechnology and Nanotechnology Research Centre, MARDI Headquarters) for sharing the original culture of Erwinia mallotivora strain BT-MARDI and Mohd Nizam Zubir (Horticultural Research Centre, MARDI Pontian) and Mohd Azhar Hassan (Horticultural Research Centre, MARDI Headquarters) for supplying Carica papaya cv. Eksotika I seedlings. We also extend our appreciation to Muhammad Saupi Azuri, Iffah Khalidah Suryani Rohaidi and Nur Nabihah Ahmad Rafie for their assistance in the final proofreading of the manuscript.

Conflicts of Interest: The authors declare no conflict of interest. The funders had no role in the design of the study; in the collection, analyses, or interpretation of data; in the writing of the manuscript, or in the decision to publish the results.

\section{References}

1. Walterson, A.M.; Stavrinides, J. Pantoea: Insights into a highly versatile and diverse genus within the Enterobacteriaceae. FEMS Microbiol. Rev. 2015, 39, 968-984. [CrossRef] [PubMed]

2. Lane, W.J.; Darst, S.A. The structural basis for promoter -35 element recognition by the group IV $\sigma$ factors. PLOS Biol. 2006, 4, 1491-1500. [CrossRef]

3. Redford, P.; Welch, R.A. Role of sigma E-regulated genes in Escherichia coli uropathogenesis. Infect. Immun. 2006, 74, 4030-4038. [CrossRef] [PubMed]

4. Kazmierczak, M.J.; Wiedmann, M.; Boor, K.J. Alternative sigma factors and their roles in bacterial virulence. Microbiol. Mol. Biol. Rev. 2005, 69, 527-543. [CrossRef]

5. Lambert, C.; Till, R.; Hobley, L.; Sockett, R.E. Mutagenesis of RpoE-like sigma factor genes in Bdellovibrio reveals differential control of groEL and two groES genes. BMC Microbiol. 2012, 12,1-9. [CrossRef]

6. Helmann, J.D. The extracytoplasmic function (ECF) sigma factors. Adv. Microb. Physiol. 2002, 46, 47-110. [CrossRef]

7. Büttner, D.; Bonas, U. Who comes first? How plant pathogenic bacteria orchestrate type III secretion. Curr. Opin. Microbiol. 2006, 9, 193-200. [CrossRef]

8. Puhar, A.; Sansonetti, P.J. Type III secretion system. Curr. Biol. 2014, 24, R784-R791. [CrossRef]

9. Campbell, E.A.; Muzzin, O.; Chlenov, M.; Sun, J.L.; Olson, C.A.; Weinman, O.; Trester-Zedlitz, M.L.; Darst, S.A. Structure of the bacterial RNA polymerase promoter specificity $\sigma$ subunit. Mol. Cell 2002, 9, 527-539. [CrossRef] 
10. Choi, M.; Kim, W.; Lee, C.; Oh, C. Harpins, multifunctional proteins secreted by gram-negative plant-pathogenic bacteria. Mol. Plant-Microbe Interact. 2013, 26, 1115-1122. [CrossRef]

11. Kimbrough, T.G.; Miller, S.I. Contribution of Salmonella typhimurium type III secretion components to needle complex formation. Proc. Natl. Acad. Sci. USA 2000, 97, 11008-11013. [CrossRef] [PubMed]

12. He, S.Y.; Schoedel, C.; Chatterjee, A.K.; Collmer, A. Extracellular secretion of pectate lyase by the Erwinia chrysanthemi out pathway is dependent upon sec-mediated export across the inner membrane. J. Bacteriol. 1991, 173, 4310-4317. [CrossRef] [PubMed]

13. Wei, Z.M.; Beer, S.V. HrpL activates Erwinia amylovora hrp gene transcription and is a member of the ECF subfamily of sigma factors. J. Bacteriol. 1995, 177, 6201-6210. [CrossRef] [PubMed]

14. Nissan, G.; Manulis, S.; Weinthal, D.M.; Sessa, G.; Barash, I. Analysis of promoters recognized by HrpL, an alternative sigma-factor protein from Pantoea agglomerans pv. gypsophilae. Mol. Plant-Microbe Interact. 2005, 18, 634-643. [CrossRef] [PubMed]

15. Peng, Q.; Yang, S.; Charkowski, A.O.; Yap, M.N.; Steeber, D.A.; Keen, N.T.; Yang, C.H. Population behavior analysis of dspE and pelD regulation in Erwinia chrysanthemi 3937. Mol. Plant-Microbe Interact. 2006, 19, 451-457. [CrossRef]

16. Yang, S.; Peng, Q.; Zhang, Q.; Zou, L.; Li, Y.; Robert, C.; Pritchard, L.; Liu, H.; Hovey, R.; Wang, Q.; et al. Genome-wide identification of HrpL-regulated genes in the necrotrophic phytopathogen Dickeya dadantii 3937. PLoS ONE 2010, 5, e13472. [CrossRef]

17. Mat-Amin, N.; Bunawan, H.; Ahmad-Redzuan, R.; Jaganath, I.B. Erwinia mallotivora sp., a new pathogen of papaya (Carica papaya) in Peninsular Malaysia. Int. J. Mol. Sci. 2010, 12, 39-45. [CrossRef]

18. Ahmad-Redzuan, R.; Abu-Bakar, N.; Rozano, L.; Badrun, R.; Mat-Amin, N.; Mohd-Raih, M.F. Draft genome sequence of Erwinia mallotivora BT-MARDI, causative agent of papaya dieback disease. Genome Announc. 2014, 2. [CrossRef]

19. Abu-Bakar, N.; Badrun, R.; Rozano, L.; Ahmad, L.; Ahmad-Redzuan, R.; Mohd-Raih, M.F.; Tamizi, A.A. Identification and validation of putative Erwinia mallotivora effectors proteins via quantitative proteomics and real time analysis. J. Agric. Food. Technol. 2017, 7, 10-21.

20. Juri, N.M.; Samsuddin, A.F.; Abdul-Murad, A.M.; Tamizi, A.A.; Shaharuddin, N.A.; Abu-Bakar., N. Discovery of pathogenesis related and effector genes of Erwinia mallotivora in Carica papaya (Eksotika I) seedlings via transcriptomic analysis. Int. J. Agric. Biol. 2020, 23, 1021-1032. [CrossRef]

21. Juri, N.M.; Samsuddin, A.F.; Abdul-Murad, A.M.; Tamizi, A.A.; Hassan, M.A.; Abu-Bakar., N. In silico analysis and functional characterization of FHUB, a component of Erwinia mallotivora ferric hydroxamate uptake system. J. Teknol. 2020, 82, 83-90. [CrossRef]

22. Shapiro, L.R.; Paulson, J.N.; Arnold, B.J.; Scully, E.D.; Zhaxybayeva, O.; Pierce, N.E.; Rocha, J.; Klepac-Ceraj, V.; Holton, K.; Kolter, R. An introduced crop plant is driving diversification of the virulent bacterial pathogen Erwinia tracheiphila. mBio 2018, 9, 1-18. [CrossRef]

23. Brady, C.L.; Venter, S.N.; Cleenwerck, I.; Engelbeen, K.; Vancanneyt, M.; Swings, J.; Coutinho, T.A. Pantoea vagans sp. nov., Pantoea eucalypti sp. nov., Pantoea deleyi sp. nov. and Pantoea anthophila sp. nov. Int. J. Syst. Evol. Microbiol. 2009, 59, 2339-2345. [CrossRef]

24. Ades, S.E.; Grigorova, I.L.; Gross, C.A. Regulation of the alternative sigma factor sigma (E) during initiation, adaptation, and shutoff of the extracytoplasmic heat shock response in Escherichia coli. J. Bacteriol. 2003, 185, 2512-2519. [CrossRef] [PubMed]

25. De Las Peñas, A.; Connolly, L.; Gross, C.A. The sigmaE-mediated response to extracytoplasmic stress in Escherichia coli is transduced by RseA and RseB, two negative regulators of sigmaE. Mol. Microbiol. 1997, 24, 373-385. [CrossRef] [PubMed]

26. Campbell, E.A.; Tupy, J.L.; Gruber, T.M.; Wang, S.; Sharp, M.M.; Gross, C.A.; Darst, S.A. Crystal structure of Escherichia coli sigmaE with the cytoplasmic domain of its anti-sigma RseA. Mol. Cell. 2003, 11, 1067-1078. [CrossRef]

27. Tam, C.; Collinet, B.; Lau, G.; Raina, S.; Missiakas, D. Interaction of the conserved region 4.2 of $\varsigma \mathrm{E}$ with the RseA anti-sigma factor. J. Biol. Chem. 2002, 277, 27282-27287. [CrossRef]

28. Janin, J.; Bahadur, R.P.; Chakrabarti, P. Protein-protein interaction and quaternary structure. Q. Rev. Biophys. 2008, 41. [CrossRef]

29. Erijman, A.; Rosenthal, E.; Shifman, J.M. How structure defines affinity in protein-protein interactions. PLoS ONE 2014, 9, e110085. [CrossRef] 
30. Schechter, L.M.; Vencato, M.; Jordan, K.L.; Schneider, S.E.; Schneider, D.J.; Collmer, A. Multiple approaches to a complete inventory of Pseudomonas syringae pv. tomato DC3000 type III secretion system effector proteins. Mol. Plant-Microbe Interact. 2006, 19, 1180-1192. [CrossRef]

31. Tang, X.; Xiao, Y.; Zhou, J.M. Regulation of the type III secretion system in phytopathogenic bacteria. Mol. Plant-Microbe Interact 2006, 19, 1159-1166. [CrossRef] [PubMed]

32. Campagne, S.; Allain, F.H.T.; Vorholt, J.A. Extra Cytoplasmic Function sigma factors, recent structural insights into promoter recognition and regulation. Curr. Opin. Struct. Biol. 2015, 30, 71-78. [CrossRef]

33. Mascher, T. Signaling diversity and evolution of extracytoplasmic function (ECF) $\sigma$ factors. Curr. Opin. Microbiol. 2013, 16, 148-155. [CrossRef] [PubMed]

34. Missiakas, D.; Raina, S. The extracytoplasmic function sigma factors: Role and regulation. Mol. Microbiol. 1998, 28, 1059-1066. [CrossRef] [PubMed]

35. Flynn, J.M.; Levchenko, I.; Sauer, R.T.; Baker, T.A. Modulating substrate choice: The SspB adaptor delivers a regulator of the extracytoplasmic-stress response to the AAA+ protease ClpXP for degradation. Genes Dev. 2004, 18, 2292-2301. [CrossRef] [PubMed]

36. Lonetto, M.; Gribskov, M.; Gross, C.A. The sigma 70 family: Sequence conservation and evolutionary relationships. J. Bacteriol. 1992, 174, 3843-3849. [CrossRef]

37. Paget, M.S.B.; Helmann, J.D. The $\sigma 70$ family of sigma factors. Genome Biol. 2003, 4, 1-6. [CrossRef]

38. Nagai, H.; Shimamoto, N. Regions of the Escherichia coli primary sigma factor $\sigma 70$ that are involved in interaction with RNA polymerase core enzyme. Genes Cells 1997, 2, 725-734. [CrossRef]

39. Malhotra, A.; Severinova, E.; Darst, S.A. Crystal structure of a sigma 70 subunit fragment from Escherichia coli RNA polymerase. Cell 1996, 87, 127-136. [CrossRef]

40. Jovanovic, M.; Waite, C.; James, E.; Synn, N.; Simpson, T.; Kotta-Loizou, I.; Buck, M. Functional characterization of key residues in regulatory proteins HrpG and HrpV of Pseudomonas syringae pv. tomato DC3000. Mol. Plant-Microbe Interact. 2017, 30, 656-665. [CrossRef]

41. Chatterjee, A.; Cui, Y.; Chatterjee, A.K. Regulation of Erwinia carotovora hrpLEcc (sigma-LEcc), which encodes an extracytoplasmic function subfamily of sigma factor required for expression of the HRP regulon. Mol. Plant-Microbe Interact. 2002, 15, 971-980. [CrossRef] [PubMed]

42. Boldrin, F.; Cioetto Mazzabò, L.; Anoosheh, S.; Palù, G.; Gaudreau, L.; Manganelli, R.; Provvedi, R. Assessing the role of Rv1222 (RseA) as an anti-sigma factor of the Mycobacterium tuberculosis extracytoplasmic sigma factor SigE. Sci. Rep. 2019, 9, 4513. [CrossRef] [PubMed]

43. Johnson, C.M.; Fisher, D.J. Site-specific, insertional inactivation of incA in Chlamydia trachomatis using a group II intron. PLoS ONE. 2013, 8, e83989. [CrossRef] [PubMed]

44. Ando, M.; Yoshimatsu, T.; Ko, C.; Converse, P.J.; Bishai, W.R. Deletion of Mycobacterium tuberculosis sigma factor E results in delayed time to death with bacterial persistence in the lungs of aerosol-infected mice. Infect. Immun. 2003, 71, 7170-7172. [CrossRef]

45. Supian, S.; Saidi, N.B.; Wee, C.; Abdullah, M.P. Antioxidant-mediated response of a susceptible papaya cultivar to a compatible strain of Erwinia mallotivora. Physiol. Mol. Plant Pathol. 2017, 98, 37-45. [CrossRef]

(C) 2020 by the authors. Licensee MDPI, Basel, Switzerland. This article is an open access article distributed under the terms and conditions of the Creative Commons Attribution (CC BY) license (http://creativecommons.org/licenses/by/4.0/). 